Family Profile No. 29

\title{
Marriage in the U.S.: Twenty-five Years of Change, 1995-2020
}

Author: Lisa Carlson

The marriage rate in the U.S. has fallen over the last 25 years, while the rate of premarital cohabitation has increased (Cherlin 2020; FP-17-05). In 1995, the marriage rate was about 45 per 1,000 women, falling to about 31 per 1,000 women by 2020 (FP-2021). Using data from the 1995 and 2020 Current Population Survey, this family profile investigates 25 years of change in marriage among women aged 18-49. Updating FP-15-17, the profile also examines variation in the share of women ever married by age, race/ethnicity, and educational attainment.

\section{Age Variation}

- Between 1995 and 2020, the share of women ever married decreased by 15 percentage points (from $72 \%$ to $57 \%$ ).

- The proportion of women between 18-49 who ever married decreased for all age groups.

- The relative size of the decrease between 1995 and 2020 was largest for women aged 18-24 and smallest for women aged 45-49.

○ For women aged 18-24, the proportion of women ever married was about $60 \%$ smaller in 2020 compared with 1995 (26\% to $10 \%$, respectively).

Figure 1. Twenty-five Years of Change in the Share of Women (18-49) Who Ever Married by Age at Interview

For women aged 45-49, the share of women ever married decreased by 7 percentage points between 1995 and 2020 (about 8\% smaller).
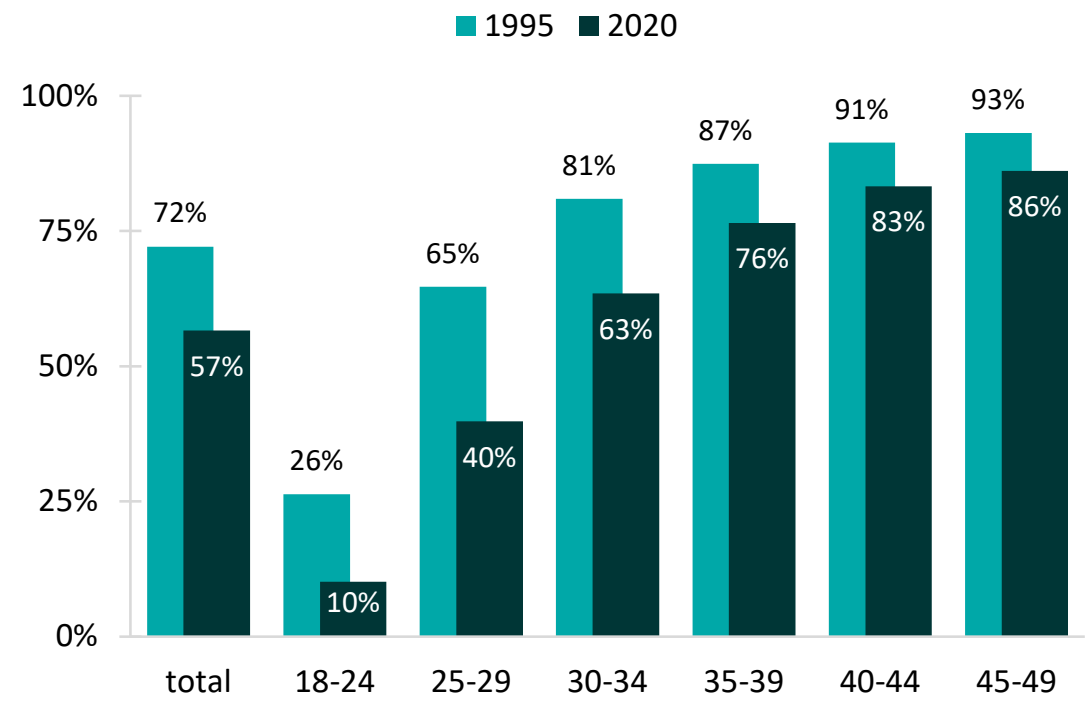

Source: NCFMR analyses of Current Population Survey (IPUMS) 1995 and 2020 March Supplements

\section{Race \& Ethnicity}

Figure 2: Twenty-five Years of Change in the Share of Women (1849) Who Ever Married by Racial/Ethnic Status

$$
\square 1995 \square 2020
$$

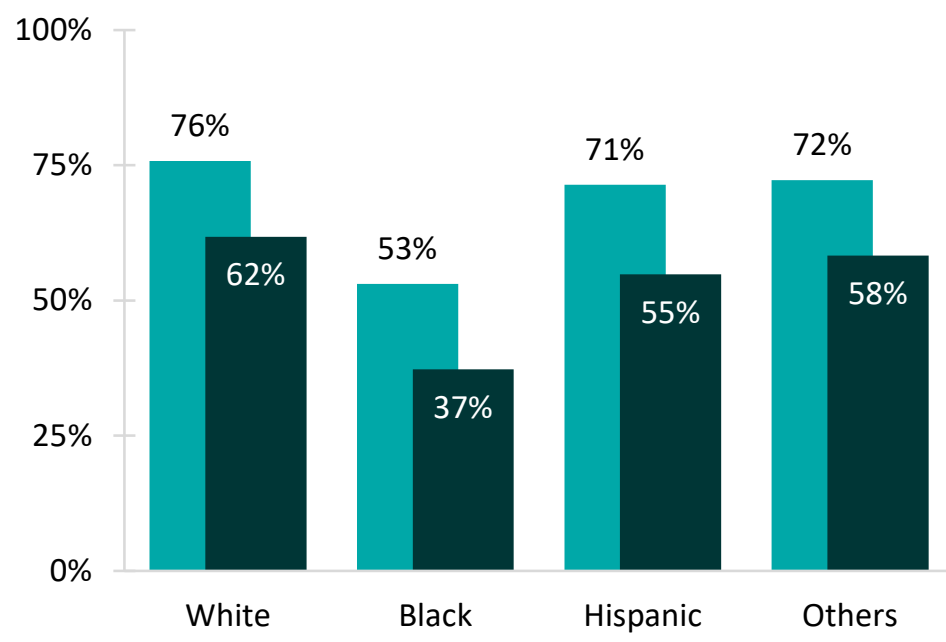

Source: NCFMR analyses of Current Population Survey (IPUMS) 1995 and 2020 March Supplements
- The share of women ever married decreased between 1995 and 2020 for all racial and ethnic groups.

- The change in the proportions of women ever married between 1995 and 2020 differed across racial/ethnic groups.

- The shares of White women, Hispanic women and women in the 'Other' racial/ethnic group were all around one-fifth smaller in $\mathbf{2 0 2 0}$ compared to 1995 , with the greatest decline in the share for Hispanic women $22.5 \%$ compared to $18.4 \%$ for White women and $19.4 \%$ for women of Other races/ethnicities).

0 The proportion of women ever married declined the most among Black women for whom the proportion was 30\% smaller in 2020 than in 1995 (37\% versus 53\%). 


\section{Educational Attainment}

- The proportion of women ever married declined from 1995 to 2020 for all levels of educational attainment.

- The decline in the share of women ever married differed across education levels.

- The largest decrease in the proportion ever married was among women with a high school degree. In 2020, the proportion was about twothirds of the proportion in 1995 (52\% versus 77\%).

- The decline in the share ever married for those with less than a high school diploma and those who had some college education were about a quarter smaller in 2020 compared to 1995 (decreased by $25 \%$ and $27 \%$, respectively).

- Among women with at least a bachelor's degree, the decline between 1995 and 2020 was about one-third as large as the decline among women with a high school degree (declines of $12 \%$ and $32 \%$, respectively).
Figure 3: Twenty-five Years of Change in the Share of Women (18-49) Who Ever Married by Educational Attainment

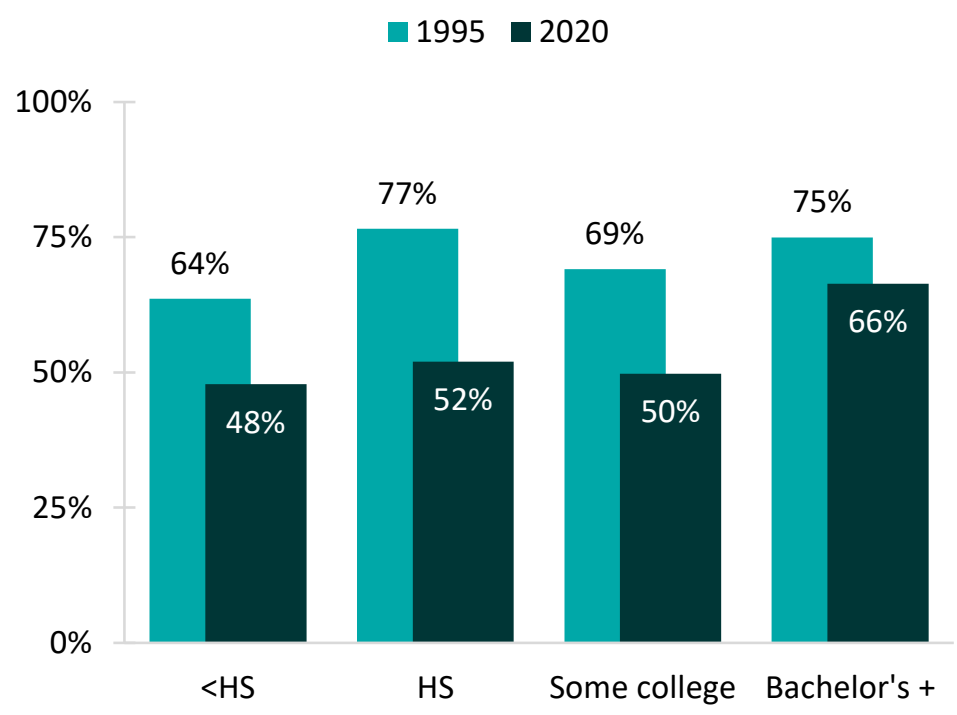

Source: NCFMR analyses of Current Population Survey (IPUMS) 1995 and 2020 March Supplements

\section{Between 1995 and 2020, the share of women ever married decreased by 15 percentage points (from $72 \%$ to $57 \%$ ).}

\section{References:}

Cherlin, A. J. (2020). Degrees of change: An assessment of the deinstitutionalization of marriage thesis. Journal of Marriage and Family, 82(1), 62-80.

Flood, S., King, M., Rodgers, R., Ruggles, S., \& Warren, R. (2020). Integrated Public Use Microdata Series, Current Population Survey: Version 8.0 [dataset]. Minneapolis, MN: IPUMS, 2020. https://doi.org/10.18128/D030.V8.0

Hemez, P. \& Manning, W. D. (2017). Thirty years of change in women's premarital cohabitation experience. Family Profiles, FP-1705. Bowling Green, OH: National Center for Family \& Marriage Research.

http://www.bgsu.edu/ncfmr/resources/data/familyprofiles/hemez-manning-30-yrs-change-women-premarital-cohab-fp17-05.html

Lamidi, E. (2015). Marriage in the U.S.: Twenty-five Years of Change, 1989-2014. Family Profiles, FP-15-17. Bowling Green, OH: National Center for Family \& Marriage Research. http://www.bgsu.edu/ncfmr/resources/data/family-profiles/lamidimarriage-25-yrs-change-fp-15-17

Schweizer, V. J. (2020). Marriage: More than a century of change. Family Profiles, FP-20-21. Bowling Green, OH: National Center for Family \& Marriage Research. https://doi.org/10.25035/ncfmr/fp-20-21

\section{Suggested Citation:}

Carlson, L. (2020). Marriage in the U.S.: Twenty-five years of change, 1995-2020. Family Profiles, FP-20-29. Bowling Green, OH: National Center for Family \& Marriage Research. https://doi.org/10.25035/ncfmr/fp-20-29 